\title{
Movement of Retinal Terminals in Goldfish Optic Tectum Predicted by Analysis of Neuronal Proliferation
}

\author{
Pamela A. Raymond \\ Department of Anatomy and Cell Biology, University of Michigan Medical School, Ann Arbor, Ml 48109-0010
}

Quantititative, computer-assisted autoradiography was used to assess the relative rate and pattern of growth of retina and tectum in larval and early juvenile goldfish. ${ }^{3} \mathrm{H}$-thymidine was used to mark the boundary of retina and tectum, and the location of this boundary was charted as the eye and brain grew and added more cells. The pattern of growth is at all times discordant. The original (larval) retina becomes surrounded by annuli of new tissue, whereas the larval tectum remains adjacent to the rostral edge as crescents of new tissue are added to the caudal end. After 2 years of growth, more than $95 \%$ of the total surface area of retina and tectum in goldfish derives from cells born after larval stages. Computer-aided reconstructions of ${ }^{3} \mathrm{H}$-thymidine labeled retina and tecta were used to predict the direction and magnitude of displacement of the retinotopic map. It was estimated that retinal terminals can shift 1.5-1.8 mm caudally at a rate of $5 \mu \mathrm{m} / \mathrm{d}$ during the first 2 years of growth. The terminals that move the farthest are those from temporal retina that project to rostral tectum. The magnitude and direction of the predicted movements matches certain features of HRP-filled retinal axons that others have assumed represented the history of displacements of the terminal arbors.

The synaptic connections formed by growing nerve fibers in the developing brain are typically less selective and more diffuse than are the connections made by those same fibers after maturation of the brain is completed (Jones, 1981; LeVay et al., 1980; Lichtman and Purves, 1980). Numerous examples of this phenomenon have been reported in many different regions of the nervous system in a variety of animals, and it has come to be accepted as a general principle of neuronal development in vertebrates. In most cases, the definitive synaptic relations of a given neuron are included as a subset of the earlier, more widespread terminal arbor, and the process of maturation involves pruning of superfluous or inappropriate branches. A somewhat different sequence of events is thought to occur in the retinotectal pathway in fish and amphibians.

Straznicky and Gaze (1972) first postulated that during development of the retinotectal projection in Xenopus tadpoles, synaptic connections of retinal terminals are formed and then

\section{Received June 27, 1985; revised Feb. 21, 1986; accepted Feb. 24, 1986}

$\mathrm{Mr}$.James Kilgore developed and implemented the software for the computer reconstructions, and without his persistence and dedication it would not have been possible to accomplish this aspect of the project. We are grateful to Drs Thomas Connelly and Fred Bookstein for generously providing a prototype version of the PLOTTER program and for offering advice and assistance during its further development. Dr. Eric Grinberg assisted with the mathematical derivations. Ms Laurie Sultz, Ms. Patricia Rivlin, and Mr. Joseph Wissing provided excellent technical assistance. Dr. Stephen S. Easter, Jr., commented on the manuscript. This work was supported by NIH Grant EY 04318; the author is a Fellow of the Alfred P. Sloan Foundation and has published previously under the name P. R. Johns.

Correspondence should be addressed to Dr. Pamela A. Raymond at the above address.

Copyright (C) 1986 Society for Neuroscience $0270-6474 / 86 / 092479-10 \$ 02.00 / 0$ broken and reformed in another location. They suggested that continuous readjustment of retinotectal connectivity was necessary because of the differing modes of growth of retina and tectum: The retina in Xenopus tadpoles grows by addition of concentric rings of new neurons at the peripheral margin (Straznicky and Gaze, 1971), whereas the optic tectum grows by addition of bands of new cells at the caudomedial boundary (Straznicky and Gaze, 1972). Thus, the population of retinal terminals shifts caudally to colonize new areas of tectum while maintaining retinotopic order among themselves. Further experiments provided additional support for this hypothesis (Chung et al., 1974; Gaze et al., 1974). Scott and Lazar (1976) attempted to demonstrate movement of retinal terminals directly by labeling them with radioactive amino acid ( ${ }^{3} \mathrm{H}$-proline) injected intraocularly, while, at the same time, the animal was injected intraperitoneally with ${ }^{3} \mathrm{H}$-thymidine to label the dividing cells in the germinal zone at the boundary of the tectum. At earlier times, the radioactive terminals covered the tectum up to the boundary marked by the thymidine-labeled tectal cells; later (4 weeks), the labeled terminals spread caudally up to about 250 $\mu \mathrm{m}$ beyond the thymidine-labeled zone.

Not all evidence has been so supportive, however (Jacobson, 1976), and the hypothesis of shifting retinotectal connections remained controversial for many years. Jacobson (1977) reported that his studies using the same double-labeling technique that Scott and Lazar (1976) had used failed to demonstrate shifting of labeled retinal terminals into new regions of tectum. More recent papers have all supported the hypothesis (Fraser, 1983; Gaze et al., 1979; Longley, 1978).

On balance, the evidence suggests that the retinotopic map shifts caudally and medially by a few hundred micrometers as Xenopus tadpoles grow. The magnitude of the movement is roughly equivalent to the average size of the terminal arbor of a single retinal fiber (Lazar, 1973). When viewed with this perspective, the proposed shifts in connectivity are perhaps less impressive. A recent series of papers by Reh and ConstantinePaton and colleagues (Constantine-Paton et al., 1983; Reh and Constantine-Paton, 1983, 1984) have documented a similar mismatch in the mode of retinal and tectal growth in developing Rana pipiens tadpoles, but in this species the shifts in position of retinal terminals are substantially larger, on the order of 1.4 mm during a 6 week period (Reh and Constantine-Paton, 1984). The movements were quantified with a double-labeling technique, in which the boundary of the tectum was marked with ${ }^{3} \mathrm{H}$-thymidine at an early larval stage, and the terminals of retinal fibers were identified using anterograde transport of HRP. The position of the labeled retinal terminals with respect to the band of ${ }^{3} \mathrm{H}$-thymidine-labeled tectal cells was later assessed at various times, and was observed to have moved caudally.

Another animal in which growth-related shifts in the retinotectal map are thought to occur is the goldfish (Meyer, 1978). Neuronal cell addition continues in the retina (Johns, 1977; Johns and Easter, 1977) and optic tectum (Raymond and Easter, 
1983) of adult goldfish up to at least 4 or 5 years of age. The pattern of growth is incongruent throughout this period: The retina adds concentric rings of new cells (Johns, 1977; Meyer, 1978), and the tectum adds crescents of tissue at the caudomediolateral boundary (Kirsche and Kirsche, 1961; Meyer, 1978; Raymond and Easter, 1983). Although we know how retina and tectum grow in juvenile and adult goldfish, information about growth in larval and early juvenile stages is available only for the retina (Johns, 1982). To understand how the retinotectal map is organized and to predict how retinal fibers might shift as new cells are added to the tectum, it is necessary to quantify the amount and pattern of tectal growth in younger fish. That is the purpose of the present study. A preliminary report of some of these results has been published (Raymond, 1983).

\section{Materials and Methods}

\section{Experimental protocol and histology}

Adult goldfish obtained from Ozark Fisheries (Stoutland, MO) were spawned in the laboratory, and the embryos were maintained as described previously (Raymond, 1985). Larval fish were reared in artificial pond water (Allee et al., 1940) and fed live nauplii of brine shrimp (Artemia). Beginning about 1 month after hatching, the diet was supplemented with finely ground Purina Trout Chow. Fish about 1 year of age or older were fed Trout Chow and live Tubifex worms.

Throughout this report the age of the fish is expressed as days after hatching. Larval development in goldfish kept at $21^{\circ} \mathrm{C}$ lasts about 3 weeks (Kajishima, 1960). The morphological changes that take place during this period are gradual, and there are no obvious changes in the structure of retina or brain associated with the stages of larval development or with metamorphosis. However, to be precise, animals less than 3 weeks old will be referred to as "larvae," and animals between 3 weeks and 1 year of age will be called "juveniles." Animals older than a year are capable of reproductive activity, and could therefore be "adults," although goldfish often do not spawn until 2 or more years of age (Matsui, 1981). It is customary to refer to small fish, less than about $8-10 \mathrm{~cm}$ body length, as "juveniles" since the exact age and reproductive status are typically not known.

Larval and early juvenile fish were injected with approximately $1 \mu \mathrm{Ci}$ of ${ }^{3} \mathrm{H}$-thymidine (80-100 Ci/mmol; New England Nuclear) $12-50 \mathrm{~d}$ after hatching. One fish was given 2 doses of ${ }^{3} \mathrm{H}$-thymidine a week apart. Animals were first anesthetized with $0.01 \%$ tricaine methanesulfonate, and the isotope was injected intraperitoneally with a micropipet as described previously (Johns, 1982). Survival periods ranged from $24 \mathrm{hr}$ to 20 months.

Small fish were fixed whole in $2.5 \%$ glutaraldehyde, $1-2.5 \%$ paraformaldehyde, $0.1 \%$ picric acid in $0.1 \mathrm{M}$ phosphate buffer overnight at $4^{\circ} \mathrm{C}$; larger fish were decapitated and the heads placed in the same fixative. All animals were deeply anesthetized before they were killed. Following fixation, the eyes and brains were dissected out of larger specimens, and smaller animals were decapitated. Tissues were dehydrated in graded ethanols and embedded in Sorvall embedding medium (Polysciences). Serial sections were cut at $3 \mu \mathrm{m}$ and mounted on slides. Most eyes were cut parallel to the dorsoventral axis (vertically), but a few were cut parallel to the nasotemporal axis (horizontally). Brains were cut either transversely or sagittally. Slides were processed for autoradiography using Kodak NTB-2 emulsion as described previously (Johns, 1982). I inear histological shrinkage was estimated at $15 \%$, and all measurements were corrected accordingly.

\section{Computer-assisted reconstructions}

For each fish, one or both retinas and optic tecta were reconstructed. Camera lucida drawings were prepared of 15-35 sections spaced at equal intervals of $18-75 \mu \mathrm{m}$ (the larger the eye or brain, the greater the interval). Final magnification of the drawings ranged from $\times 28$ to $\times 170$ (the larger the specimen, the lower the magnification). The position of each thymidine-labeled cell was indicated on the drawing of each section. A cell was considered to be labeled if there were 10 or more silver grains over its nucleus. For each drawing the outlines of the retina or optic tectum and the positions of labeled cells were digitized using a Summagraphics tablet linked to a Tektronix 4054 graphics computer. Successive sections were aligned with reference to the midline (for the brain) and the boundaries of the structure being traced; labeled cells were not used for alignment purposes. For each section, its distance in micrometers from an arbitrary point at the beginning of the series was recorded in the computer data set. This data set was then transferred to the University of Michigan mainframe computer, an Amdahl 5860. A graphics program written in FORTRAN 77, called PLOTTER (Copyright, 1985, The University of Michigan) was used to produce the reconstructions, which were viewed on the screen of the Tektronix 4054 and plottcd on a CalComp plotter.

\section{Calculation of retinal and tectal surface areas}

Retinal surface area, $S$, was calculated as described previously (Easter et al., 1977; Johns, 1982) according to a geometric equation for the surface area of a partial sphere. Areas of portions of the retinal surface, bounded by annuli of thymidine-labeled cells (see below), were calculated using the same equation but with appropriate adjustment of the parameters.

The tectal surface area, $A$, was estimated from the sections as follows. The linear distance along the pial surface of the tectum from one margin to the other was measured on camera lucida drawings. For each successive pair of sections, the mean surface length was calculated, and this value was multiplied by the distance separating the 2 sections to yield the surface area of a slab of tectum bounded by the 2 sections. The sum of all the slabs was computed to give an estimate of total surface area. In those cases in which the first section in the series cut tangentially or obliquely through a curved region of the tectum (see Fig. 6 ), the area enclosed by the outline of the tectal surface on this section was added to the sum. It should be noted that the terminals of the retinal fibers are not strictly on the tectal surface but some few hundreds of micrometers below it, in the synaptic layers. However, the synaptic layers could not be easily recognized in the histological preparations used, so the pial surface of the tectum was reconstructed instead. This overestimates by $15 \%$ or less the tectal area actually receiving retinal terminals.

The results given below show that neurons labeled with ${ }^{3} \mathrm{H}$-thymidine were distributed in the tectum as a partial annulus. The majority of neurons (over 95\% according to Meek and Schellart, 1978) are in the periventricular layer (see Fig. $2 B$ ), which lies below the tectal surface, and the region of labeled cells was most readily apparent in this layer. To estimate the tectal surface area enclosed by the labeled zone, on each section that contained labeled cells, the perpendicular projection of the inner edge of the labeled segment onto the pial surface was marked, and the area of tectal surface thus delineated was calculated by summing successive slabs as described above. At the rostral edge of the tectal surface, where there were no labeled cells, the perimeter of the tectum formed the boundary. The tectal cells enclosed within this labeled region represent the original tectum, present at the time of the injection.

\section{Results}

\section{Tectal germinal zone in larval goldfish}

Shortly after an injection of ${ }^{3} \mathrm{H}$-thymidine in larval and early juvenile fish, cells with labeled nuclei are found in a germinal zone at the perimeter of both retina and tectum. The annular germinal zone of the larval goldfish retina has been described previously (Johns, 1982), but the tectal germinal zone has not. In the tectum, the germinal zone does not form a complcte annulus, as shown in the reconstructions in Figure 1. There are no labeled cells at the rostrolateral edge. We showed previously (Raymond and Easter, 1983) that the tectal germinal zone in adult goldfish has a similar shape and location. The gap in the germinal zone in the 3 tecta shown in Figure 1 subtends $81^{\circ}$, $113^{\circ}$, and $110^{\circ}$, respectively, when measured with respect to the circle that best fits the tectal perimeter and germinal zone. These values are not too different from angles of $100^{\circ}$ and $140^{\circ}$ reported previously for the corresponding measurement in 2 adult goldfish (Raymond and Easter, 1983). In the adult, the gap in the tectal germinal zone corresponds to a region at the perimeter of the nasoventral visual field, i.e., temporodorsal retina (Fig. 10 in Raymond and Easter, 1983). In retinotopic coordinates, the midpoint of the gap is $8.3^{\circ}$ dorsal to the horizontal meridian. The retinotectal projection has not been mapped in larval goldfish, so the retinotopic position of the tectal germinal zone in 
larval fish could not be determined directly. However, the relative location of the gap in the germinal zone with respect to the midline of the brain is roughly the same in larvae and adults.

The conclusion from the above results is that the pattern of cell addition in the optic tecta of adult goldfish is established at hatching and remains constant as the fish grows. Cells are generated by mitotic division in a germinal zone whose shape is a partial annulus, with the open segment pointing rostrally and slightly laterally.

\section{Spatiotemporal pattern of growth of retina and tectum}

Following a longer period of time after injection of ${ }^{3} \mathrm{H}$-thymidine, some labeled cells differentiated. They produced a discrete, stable marker of the boundary of retina or tectum at the time of injection. This is illustrated in autoradiographs of the retina and tectum from a fish, F12/42, injected with ${ }^{3} \mathrm{H}$-thymidine at $12 \mathrm{~d}$ of age and killed at $42 \mathrm{~d}$ (Figs. 2, 3). In both retina and tectum, the region enclosed within the bands of labeled cells represents the original tissue present at the time of injection, and the areas peripheral to the label contain the new cells that were added subsequently (Fig. 2). Figure 3 illustrates how retina grows by addition of annuli, and tectum grows by apposition of crescents of new cells caudally. Given in Table 1, and shown graphically in Figure 4, is the fraction of total retinal or tectal surface area present originally at the time of ${ }^{3} \mathrm{H}$-thymidine injection. With longer survival times after the injection, this fraction tends to decrease as more and more new cells are added. Note that it falls to less than 0.05 after 20 months, which means that over $95 \%$ of the surface area of retina and tectum in this 2 -year-old goldfish was generated during postlarval growth. The total area of retina increases about 150 -fold while tectal area increases about 50 -fold (Table 1).

For a given fish, the ratio of original to total tectal areas $\left(A^{\prime} /\right.$ $A)$ is in general slightly greater than the corresponding ratio of retinal areas $\left(S^{\prime} / S\right)$ (Table 1$)$. The mean difference in ratios is $12.7 \%$. The implication is that the rate of incremental growth by cell addition is greater in retina than in tectum in larval and young juvenile fish. A similar conclusion was reached earlier (Raymond and Easter, 1983) by comparing the total number of tectal neurons (Raymond and Easter, 1983) and optic axons (Easter et al., 1981) in older juvenile and adult goldfish of different sizes.

In order to evaluate quantitatively the mismatch between retinal and tectal growth, it is necessary to define its geometry more precisely. In the retina, the labeled annulus is approximately centered on the optic disc, which is located near the center of the retina. The optic disc is displaced slightly into the ventral retina, as shown in Figure $5 A$. The ratio $(D / V)$, which expresses this asymmetry, is greater than 3 in 3-d-old larvae. (A value of 1.0 would indicate symmetrical positioning of the optic disc along this axis.) The ratio falls precipitously to 1.55 in 10-d-old larvae and thereafter declines slowly until about 50 $\mathrm{d}$, when it reaches the adult value of $1.23 \pm 0.12$ (mean $\pm \mathrm{SD}$, $n=10$ ). The optic disc is positioned more symmetrically along the horizontal meridian. The nasotemporal ratio is $1.04 \pm 0.05$ (mean $\pm \mathrm{SD}, n=4$ ) in fish from $10 \mathrm{~d}$ to adulthood (Fig. $5 A$ ). The important point is that since all thymidine injections were given after larval day 10 , the relative location of the optic disc

Figure 1. Reconstructions of the left optic tecta of $3 \mathrm{fish}$, aged $2 \mathrm{~d}(A)$, $20 \mathrm{~d}(B)$, and $32 \mathrm{~d}(C)$. This view is a projection of the dorsal surface; rostral is at the $t o p$ and medial is to the right. The brains were cut transversely, and each line represents 1 section. The fish were injected with ${ }^{3} \mathrm{H}$-thymidine $24 \mathrm{hr}$ before they were killed; each small square represents the location of a labeled cell. In $B$ and $C$, heavily labeled
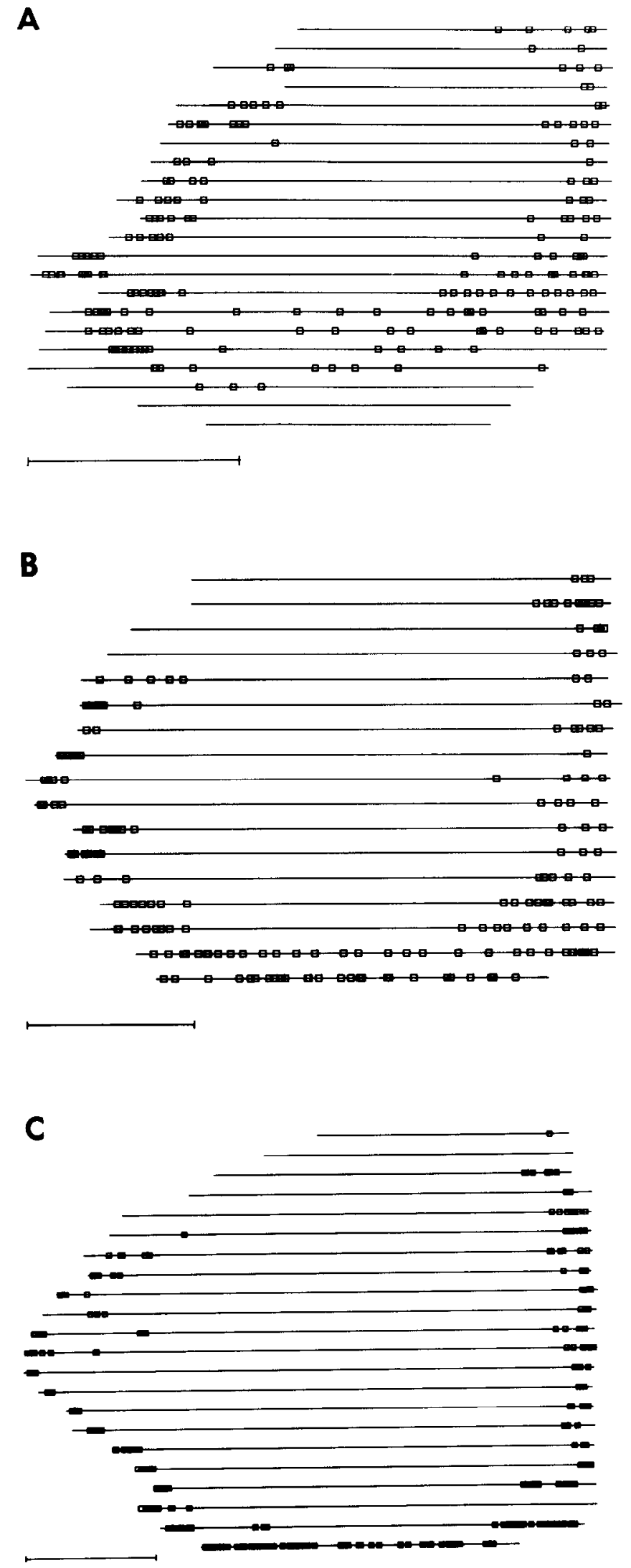

cells are found in the most caudal 1 or 2 sections; however, in $A$, the labeled zone is not at the caudal edge. The tectum caudal to the heavily labeled zone in this brain contained lightly labeled cells, indicating a more rapid rate of cell proliferation in 2-d-old compared to the 20 - or 32-d-old fish. Calibration bars, $100 \mu \mathrm{m}$. 

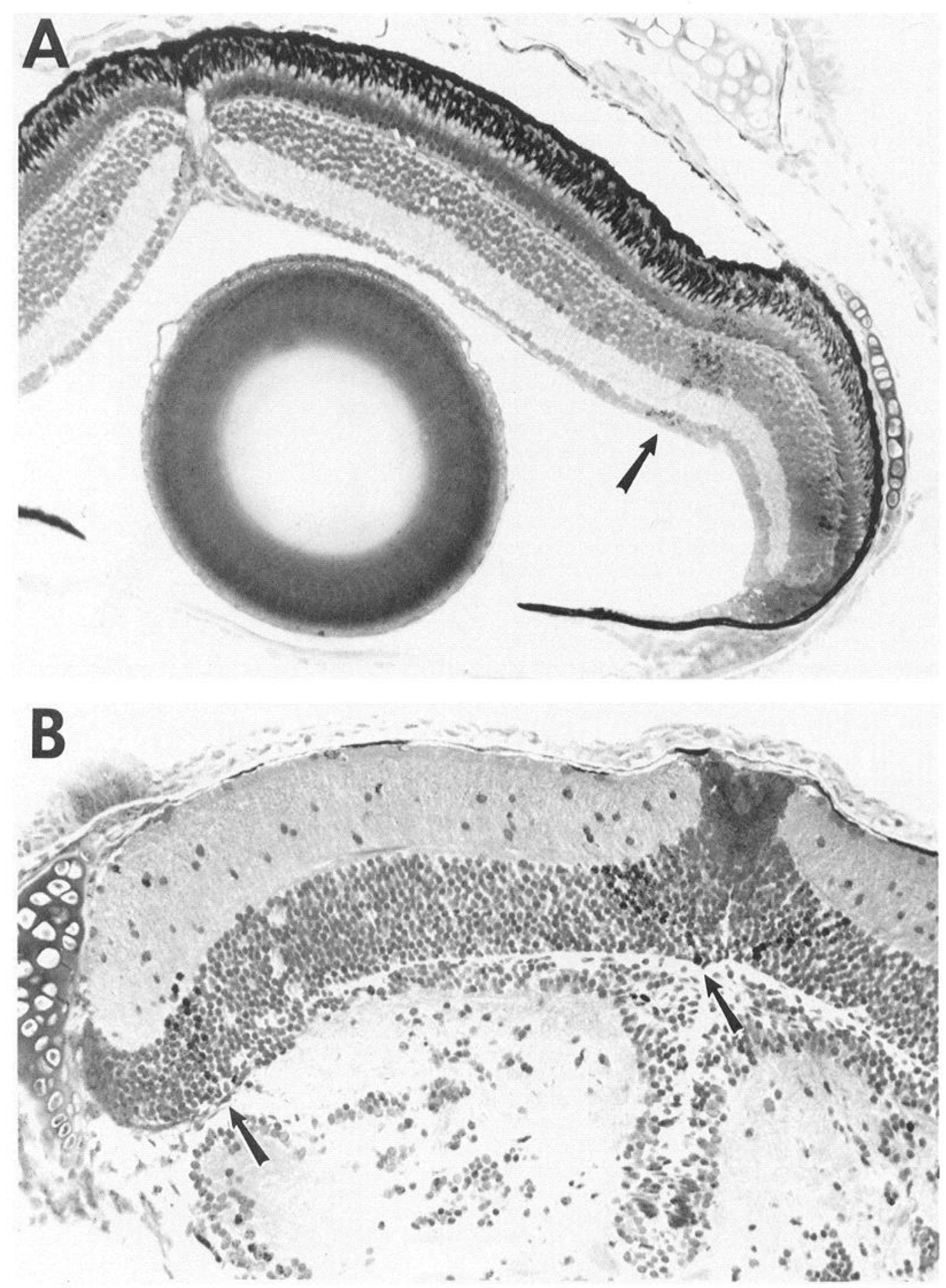

Figure 2. Autoradiographs of sections of retina $(A)$ and tectum $(B)$ from a fish, F12/42, injected with ${ }^{3} \mathrm{H}$-thymidine at $12 \mathrm{~d}$ and killed at $42 \mathrm{~d}$ of age. The labeled cells (arrows) are clustered in bands displaced from the peripheral margin on both sides of retina and tectum (only one side of the retina is shown in this micrograph).

remained approximately stable during the course of the experiments.

The eccentric position of the optic disc could be maintained by unequal cell addition along the dorsal and ventral margins, or by differential stretch of the growing retinal surface in different quadrants. The observation that cell density is not very different in dorsal and ventral halves of the goldfish retina (Johns and Easter, 1977) suggests that the former alternative is the more likely. The results from the ${ }^{3} \mathrm{H}$-thymidine experiments support this proposition. The ratio of incremental length of new retina added to dorsal and ventral margins is plotted in Figure $5 B$. The data points scatter around a ratio of $1.21 \pm 0.15$ (mean \pm $\mathrm{SD}, n=10$ ). This value is equivalent in magnitude and direction to the eccentricity of the disc in the vertical meridian (a ratio of 1.23 , Fig. $5 A$ ). The extra $20 \%$ of new retina added dorsally keeps the optic disc displaced toward the ventral margin (Fig. $5 A$ ). In the nasotemporal direction, cell addition is more nearly symmetric: The ratio of nasal to temporal is 1.07 (mean, $n=$ 
2). Likewise, the nasotemporal ratio reflecting the position of the optic disc along the horizontal meridian is 1.04 (Fig. 5A).

Cell addition in the tectum is grossly asymmetric, but in retinotopic coordinates, the axis of asymmetry is nearly orthogonal to the axis of asymmetry in retinal cell addition. As pointed out above, the center of the gap in tectal germinal zone in retinotopic coordinates is less than $10^{\circ}$ dorsal to the intersection of the horizontal meridian with the temporal edge of the retina. We can conclude that the asymmetries in retinal and tectal germinal zones match neither in position nor in magnitude.

As the tectum grows, it changes shape. The optic tectum in larval and young juvenile goldfish is relatively flat and roughly circular (Figs. 1, 3B). Between 40 and $80 \mathrm{~d}$ after hatching, the rostrolateral border begins to curl ventrally, and the tectum gradually attains its adult shape and orientation (Raymond and Easter, 1983), which is rounded rostrally and flattened caudally. The original larval tectum remains at the rostral edge and moves downward as the tectum grows until it eventually becomes hidden when the tectum is viewed from the dorsal surface. During these morphogenetic movements, the labeled zone retains its $\mathrm{C}$ shape, and it is now best seen from a rostral viewpoint on the tectal surface (Fig. 6). At all times the partial annulus of labeled tectal cells remains anchored to the rostral border of the tectal rim.

These results show that during growth of young goldfish, the larval retina becomes entirely surrounded by new retina added circumferentially, whereas the larval tectum stays adjacent to the rostral tectal rim, as new tectum is added laterally, medially, and especially caudally.

\section{Topologic considerations in support of the hypothesis of shifting terminals}

From the above description it is clear that there is a topologic mismatch in the pattern of cell addition between retina and optic tectum in goldfish from larval stages through adulthood. This premise is the basis for the supposition that in order to retain their retinotopically appropriate positions, retinal terminals must move progressively across the tectum as it grows. The data presented here provide a means to estimate the magnitude of these movements. The precision of the estimate is maximized if the following assumptions are accepted:

1. Retinal fibers terminate in retinotopic order on the tectum in larval and early juvenile fish as they do in older fish.

It is not known when optic axons initially grow into the goldfish tectum nor when functional connections are first established, but terminal arbors of retinal afferents filled with HRP have been observed in optic tecta of newly hatched zebrafish and 3- to 4-week-old goldfish (C. Stuermer and P. Raymond, unpublished observations). Furthermore, the pattern of optic fascicles in these larval brains is identical to that in adults. In developing trout larvae, Rahmann and Jeserich (1978) have shown that the period of most rapid synaptogenesis in the optic tectum takes place in the week just before the larvae begin to swim about freely, which is about $30 \mathrm{~d}$ after hatching in trout developing at $8^{\circ} \mathrm{C}$. Goldfish larvae reach the equivalent freeswimming stage about $3 \mathrm{~d}$ after hatching when maintained at $21^{\circ} \mathrm{C}$ (Kajishima, 1960), and at this time they have vigorous eye movements associated with visually directed predatory behavior ( $\mathrm{P}$. Raymond, unpublished observations). These observations support but do not prove the assumption that functional retinotectal connections are present in larval fish. There is no direct information about order or lack thereof in the retinotectal connections in larval goldfish. The smallest goldfish in which retinotectal projections have been mapped were juveniles, $5 \mathrm{~cm}$ body length (Meyer, 1978), and the retinotectal map in these small fish was organized precisely like that in adults, $12-18 \mathrm{~cm}$ body length (Schmidt et al., 1978). The 3 largest fish in the present study were more than $5 \mathrm{~cm}$ in length (Table 1), so we

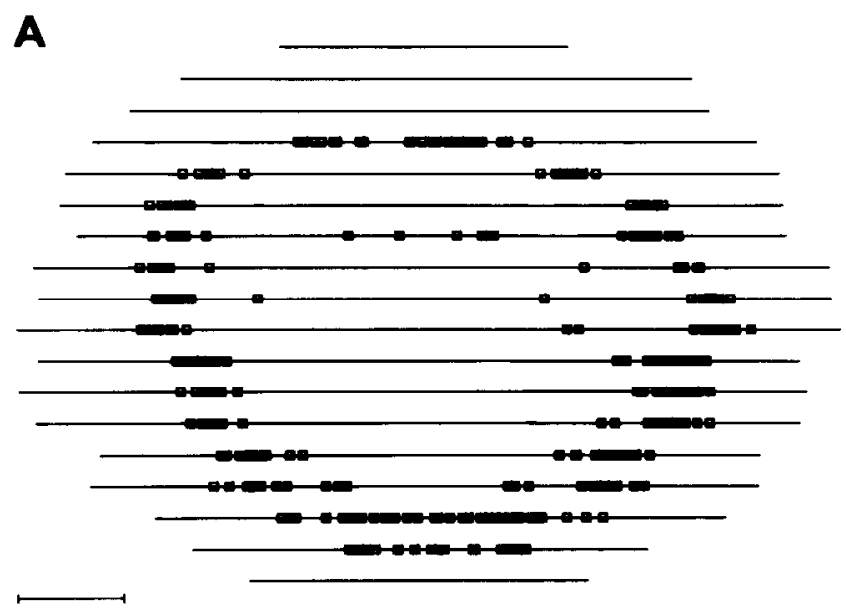

B

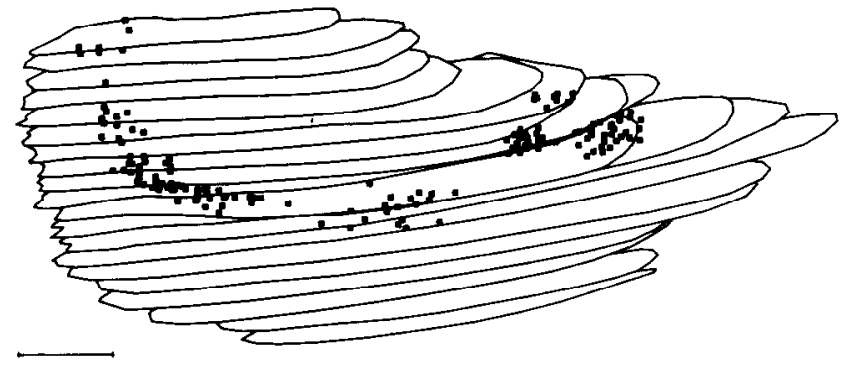

Figure 3. Reconstructions of the left retina $(A)$ and right tectum $(B)$ of fish F12/42 (also illustrated in Fig. 2). The plotting conventions are as described in Figure 1. $A$, In this orthogonal projection of the retina, each line represents 1 section cut parallel to the dorsoventral axis. The annulus of squares represents labeled cells in the circumferential germinal zone. The 10 scattered labeled cells inside the annulus are dividing rod precursors (Johns, 1982). They do not give rise to new ganglion cells, so they are not relevant for present purposes. $B$, In this perspective projection of the tectum, the view is as if the observer were looking down on the brain from a vantage point slightly in front of the tectum. Rostral is at the top and medial is to the left. Calibration bars, $100 \mu \mathrm{m}$.

can be confident that the assumption is valid at least for these animals. It is not unreasonable to assume that the map is orderly in smaller fish, since in larval amphibians retinotopic order is established shortly after retinal fibers first reach the tectum (Gaze et al., 1974; Holt and Harris, 1983).

2. The center of the retina projects to the center of the tectal surface.

This is an extension of the previous assumption and is known to be the case in juvenile (Meyer, 1977) and adult goldfish (Schmidt et al., 1978). This conclusion is based on the observation that the retinal magnification factor (degrees visual angle/ $\mathrm{mm}$ tectal surface) is nearly uniform across the tectum, which means that the center of the visual field (center of the retina) projects to the center of the tectal surface. Rusoff (1984) has also provided anatomical evidence in cichlid fish that the projection from central retina remains centered on the tectum as it grows. She used HRP to label multiple fascicles of optic axons, each derived from an annulus of ganglion cells of similar age. The resulting pattern of concentric rings of labeled retinal ganglion cells roughly centered on the optic disc was mirrored by a corresponding set of concentric rings of thcir labeled terminal arbors centered on the tectum. Thus, both morphological and 


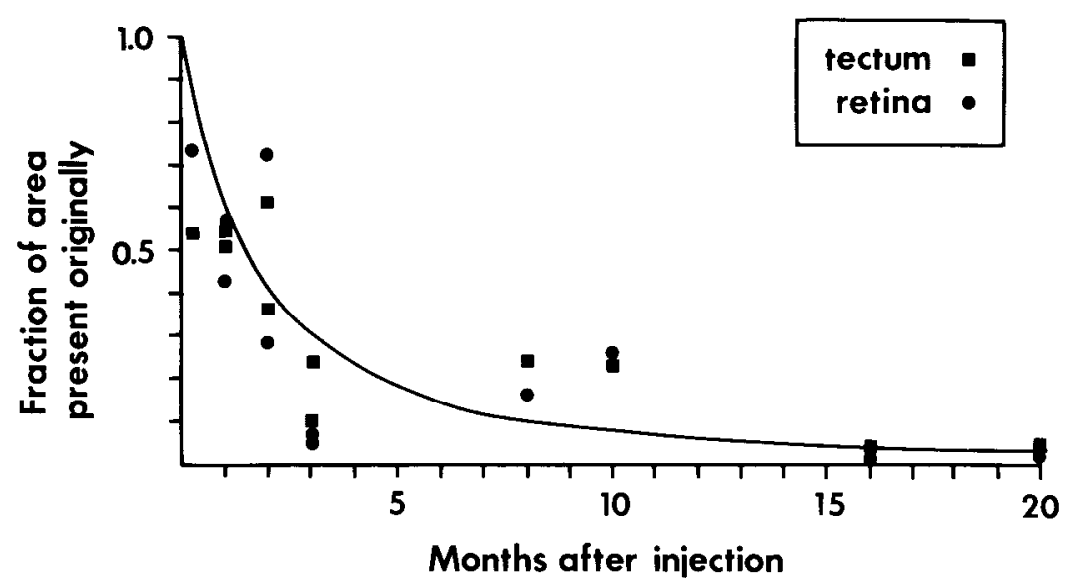

Figure 4. Fraction of total surface area of retina (filled circles) or tectum (filled squares) enclosed by the annulus or partial annulus of labeled cells plotted as a function of time in months that the fish was allowed to grow after an injection of ${ }^{3} \mathrm{H}$-thymidine. The smooth curve was fit by eye to the data points. physiological results support this assumption, though again we lack direct confirmation for the earliest period of growth in goldfish.

Because the evidence for retinotopic order in the youngest fish used here is not convincing, I will first calculate the magnitude and direction of displacement of terminals assuming order, and then evaluate the amount of potential error in the calculations that could be attributed to these assumptions. First note that those labeled retinal ganglion cells that differentiated shortly after the injection of ${ }^{3} \mathrm{H}$-thymidine, and that were at that time $\left(t_{0}\right)$ located along the perimeter of the retina, originally projected to labeled tectal cells at the tectal perimeter (Fig. 7). Fibers from the temporal retinal margin projected to the unlabeled rostral tectal margin, according to the rules of retinotopic order. Later (at time $t_{1}$ ) after growth by cell addition, the labeled zones in retina and tectum become topologically discordant; the one in retina is roughly centered on the optical disc, and the one in tectum is tangent to the rostral edge. Retinotopy dictates that the labeled retinal ganglion cells now project to an annular region approximately centered on the tectal surface (dashed circle in Fig. 7). The question is, what is the distance along the tectal surface between the location of the original tectal boundary (the site of the original projection) and the line delimited by the dashed circle (the current projection site of the original retinal cells)?

To estimate this, for each fish the total surface areas of retina and tectum are calculated as described in Materials and Methods (Table 1). The region enclosed by the labeled annulus (retina) or partial annulus (tectum) represents the "original" surface at the time of injection, and its area is also calculated (Table 1). The area enclosed by the annular region to which the labeled ganglion cells eventually project (at time $t_{1}$, dashed circle in Fig. 7 ) is given by the ratio of original retinal area divided by total retinal area multiplied by total tectal area $\left(S^{\prime} / S \times A\right)$. The displacement of one set of retinal terminals, those originally projecting to the rostral tectal edge, is depicted by the arrow in Figure 7.

The cartoon in Figure 7 is a 2-dimensional representation,

Table 1. Retinal and tectal growth

\begin{tabular}{|c|c|c|c|c|c|c|c|c|c|c|}
\hline Fish $^{a}$ & $\begin{array}{l}\text { Standard } \\
\text { body } \\
\text { length } \\
\text { (cm) }\end{array}$ & $\begin{array}{l}\text { Time } \\
\text { after } \\
\text { injection } \\
\text { (months) }\end{array}$ & $\begin{array}{l}\text { Total } \\
\text { retinal } \\
\text { area }(S)^{b} \\
\left(\mathrm{~mm}^{2}\right)\end{array}$ & $\begin{array}{l}\text { Original } \\
\text { retinal } \\
\text { area }\left(\mathbf{S}^{\prime}\right)^{b} \\
\left(\mathrm{~mm}^{2}\right)\end{array}$ & $S^{\prime} / S$ & $\begin{array}{l}\text { Ratio of } \\
\text { increment } \\
\text { length }\end{array}$ & $\begin{array}{l}\text { Total } \\
\text { tectal } \\
\text { area }(A)^{d} \\
\left(\mathrm{~mm}^{2}\right)\end{array}$ & $\begin{array}{l}\text { Original } \\
\text { tectal } \\
\text { area }\left(A^{\prime}\right) \\
\left(\mathrm{mm}^{2}\right)\end{array}$ & $A^{\prime} / A$ & $\begin{array}{l}\text { Displace- } \\
\text { ment } \\
(\delta) \\
(\mathrm{mm})\end{array}$ \\
\hline \multirow[t]{2}{*}{$F 12 / 20$} & \multirow[t]{2}{*}{0.7} & \multirow[t]{2}{*}{0.25} & $0.370(\mathbf{R})$ & 0.272 & 0.735 & 1.29 (DV) & - & - & - & - \\
\hline & & & $0.340(\mathrm{~L})$ & 0.257 & 0.759 & $1.11(\mathrm{DV})$ & $0.235(\mathbf{R})$ & 0.073 & 0.541 & 0.05 \\
\hline F12/42 & 0.8 & 1 & $0.429(\mathrm{~L})$ & 0.237 & 0.552 & - & $0.197(\mathrm{R})$ & 0.107 & 0.544 & 0.08 \\
\hline \multirow[t]{2}{*}{ F19/42 } & \multirow[t]{2}{*}{0.9} & \multirow[t]{2}{*}{1} & $0.637(\mathbf{R})$ & 0.271 & 0.426 & 1.19 & $0.409(\mathrm{R})$ & 0.206 & 0.503 & 0.138 \\
\hline & & & $0.662(\mathrm{~L})$ & 0.284 & 0.428 & 1.07 (DV) & - & - & - & - \\
\hline F32/80 & 1.6 & 1.5 & $2.68 \quad(\mathrm{~L})$ & 0.758 & 0.283 & 1.17 (DV) & $1.74(\mathrm{R})$ & 0.606 & 0.348 & 0.40 \\
\hline F50/101 & 2.0 & 2 & 3.67 (L) & 2.72 & 0.741 & $1.07(\mathrm{NT})$ & $1.61 \quad(\mathrm{R})$ & 0.980 & 0.610 & 0.14 \\
\hline$F 12 \& 19 / 107$ & 2.1 & 3 & 5.92 (L) & 0.286 & 0.048 & 0.93 (DV) & $1.83(\mathrm{R})$ & 0.181 & 0.099 & 0.68 \\
\hline $\mathrm{F} 12 / 107$ & 1.6 & 3 & 3.37 (L) & 0.232 & 0.069 & $1.06(\mathrm{NT})$ & $0.84 \quad(\mathrm{R})$ & 0.264 & 0.040 & 0.93 \\
\hline $\mathrm{F} 41 / 252$ & 3.3 & 8 & $17.9 \quad(\mathrm{~L})$ & 2.92 & 0.163 & 1.46 (DV) & $6.08 \quad(\mathrm{R})$ & 1.47 & 0.245 & 1.37 \\
\hline $\mathrm{F} 40 / 350$ & 6.0 & 10 & $32.2 \quad(\mathrm{~L})$ & 8.04 & 0.250 & 1.33 (DV) & 8.14 (R) & 1.97 & 0.242 & 1.31 \\
\hline F37/533 & 8.0 & 16 & $56.8 \quad(\mathrm{R})$ & 1.59 & 0.028 & $1.15(\mathrm{DV})$ & $11.08(\mathrm{~L})$ & 0.370 & 0.038 & 1.83 \\
\hline $\mathrm{F}<50 / 646$ & 5.4 & 20 & $31.7 \quad(\mathrm{R})$ & 1.79 & 0.056 & 1.19 (DV) & $5.95 \quad(\mathrm{~L})$ & 0.258 & 0.043 & 1.51 \\
\hline
\end{tabular}

${ }^{a}$ Each fish is identified by 2 numbers: The first is the age in days when injected with ${ }^{3} \mathrm{H}$-thymidine, and the second is the age when killed. Fish F12 \& $19 / 107$ was injected twice, at 12 and $19 \mathrm{~d}$. Fish $\mathrm{F}<50 / 646$ was injected once when it was less than $50 \mathrm{~d}$ old.

${ }^{6}$ Total retinal area $(S)$ and original retina area $\left(S^{\prime \prime}\right)$ were calculated as described in the text. The letters $(\mathrm{R})$ and $(\mathrm{L})$ following each entry indicate right or left retina, respectively.

c The ratio of the increment of new retina added at the dorsal margin divided by the increment added ventrally is denoted by entries followed by (DV). Similar ratios of increments added nasally versus temporally are denoted by (NT).

"Total tectal area $(A)$ and original tectal area $\left(A^{\prime}\right)$ were calculated as described in the text. The letters $(\mathrm{R})$ and $(\mathrm{L})$ following each entry indicate right or left tectum, respectively. 


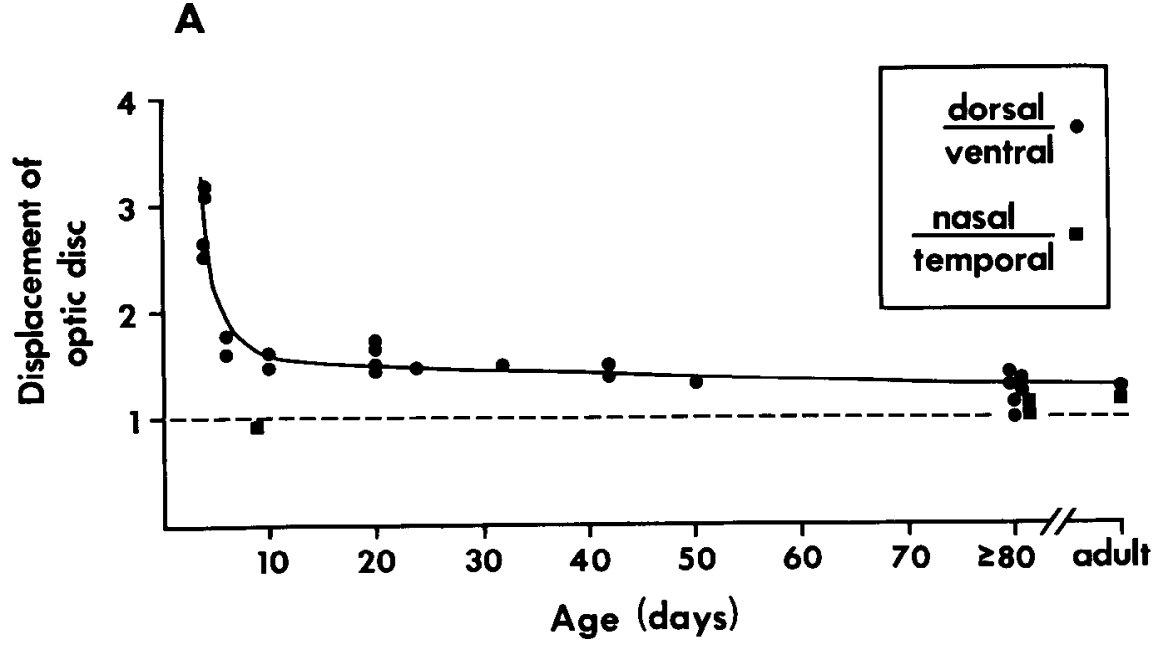

B

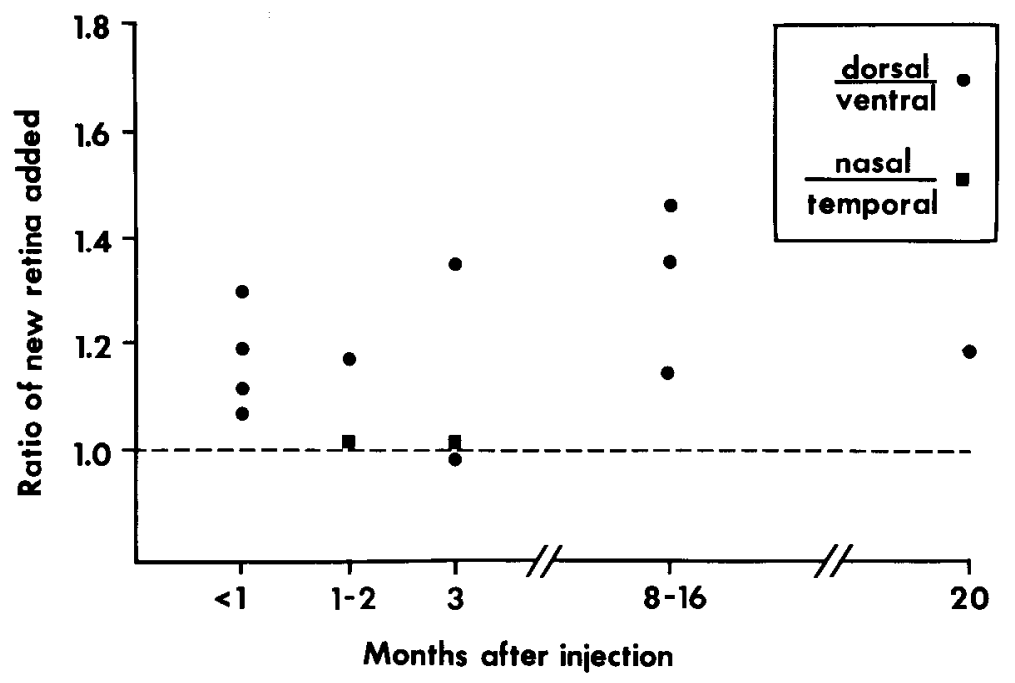

Figure 5. A, Displacement of the optic disc toward the ventral side of the retina is expressed as the ratio of the length of retina from the disc to the dorsal retinal margin divided by length of retina from disc to the ventral margin (filled circles). Measurements were made in meridional sections cut parallel to the dorsoventral axis. The curve was fit by eye to the data points (filled circles). Similarly, displacement of the disc toward the temporal side is the ratio of the length of retina from disc to nasal margin divided by length to the temporal margin in meridional sections cut parallel to the nasotemporal axis (filled squares). No curve is drawn through these points. Each point represents one retina. The age of the fish is indicated on the abscissa. $B$, Asymmetry in cell addition along the retinal germinal zone is shown as the ratio of the length of new retina added dorsally divided by the increment added ventrally (filled circles). Similarly, the ratio of the length added nasally divided by length added temporally (filled squares) is plotted as a function of time after an injection of ${ }^{3} \mathrm{H}$-thymidine. but in actuality the tectum is not flat, and the terminals move along a curved trajectory. The curved tectal surface can be represented mathematically by measuring on the tectal reconstructions the radius of curvature of the rostral half of the tectal surface. (Recall that the curvature varies both with age - tecta in the younger fish are flatter - and with tectal region - the rostral end is more curved than the caudal.) The radius of curvature defines a sphere, a portion of whose surface represents the (measured) surface area of the tectum. This spherical representation provides a good fit for the rostral half and a rather less good fit for the caudal half of the tectum, but since the displacements we are attempting to estimate take place in rostral tectum, this model is adequate (also see Meyer, 1977). The advantage of the spherical representation is that distances along its surface from one defined point to another can be calculated with spherical geometry.

The lengths of the displacement $(\delta)$ of retinal terminals from the rostral tectal edge to a new position in central tectum, as shown in Figure 7, are given for each fish in Table 1 and are graphed in Figure 8. In general, the longer the period of growth, the larger the displacement. The most rapid rate of movement seems to take place in the first few months, but this probably reflects the actual age of the fish, rather than length of survival after the injection, since fish killed between 1 and 3 months after the injection were younger and probably growing more rapidly than those killed after 2 years. When all the data are considered together, the rate of movement of retinal terminals averages $5.3 \mu \mathrm{m} / \mathrm{d}$ (range, $2.2-8.9 \mu \mathrm{m} / \mathrm{d}, n=11$ ).

The values of $\delta$ depicted in Table 1 and Figure 8 can be viewed as maximum displacements over the course of each experiment. This is because fibers that originally terminate at the rostral edge of the tectum move further than do others in their age cohort. The reason for this is that the rate of growth by cell addition is slightly greater in retina compared to tectum (Fig. 4), so the circle that represents the locus of current projection sites of the annulus of thymidine-labeled ganglion cells (dashed circle in Fig. 7) has a smaller diameter than the circle that represents the original projection sites of the same fibers (the original tectal boundary). Thus, the movement of retinal terminals in the tectum has a compressive component (more new retinal fibers added than new tectal cells). Consequently, terminals that start from the most rostral part of the tectum (corresponding to temporal retina) must move farther than other, more caudally placed, terminals of the same age. 
Figure 6. Reconstructions of 2 tecta: $A$, right tectum from fish $\mathrm{F} 50 / 101$ ( $2.0 \mathrm{~cm}$ standard body length), and $B$ left tectum from fish F41/252 $(3.3 \mathrm{~cm}$ standard body length). Both brains were cut sagittally. The view is as if the observer were standing in front of the fish looking at the rostral end of the tectum; dorsal is $u p$ in $A$ and $B$, and medial is to the right in $A$ and to the left in $B$. Labeled cells are again indicated by small squares. Calibration bars, $1 \mathrm{~mm}$.
A

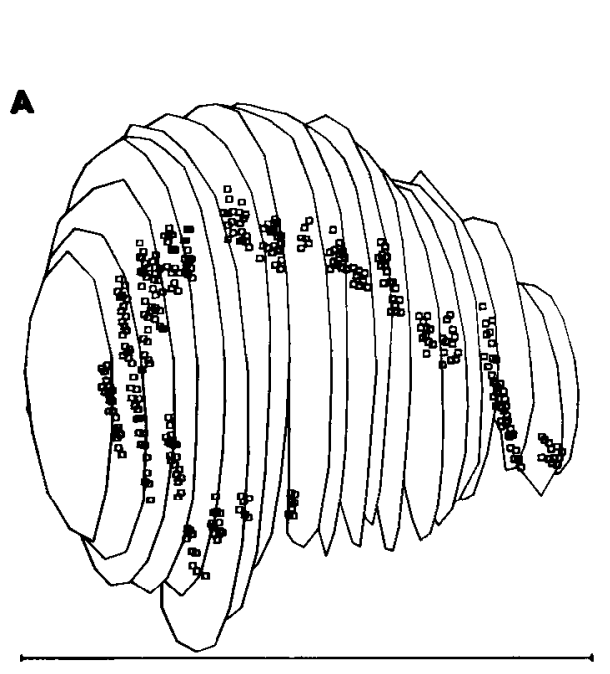

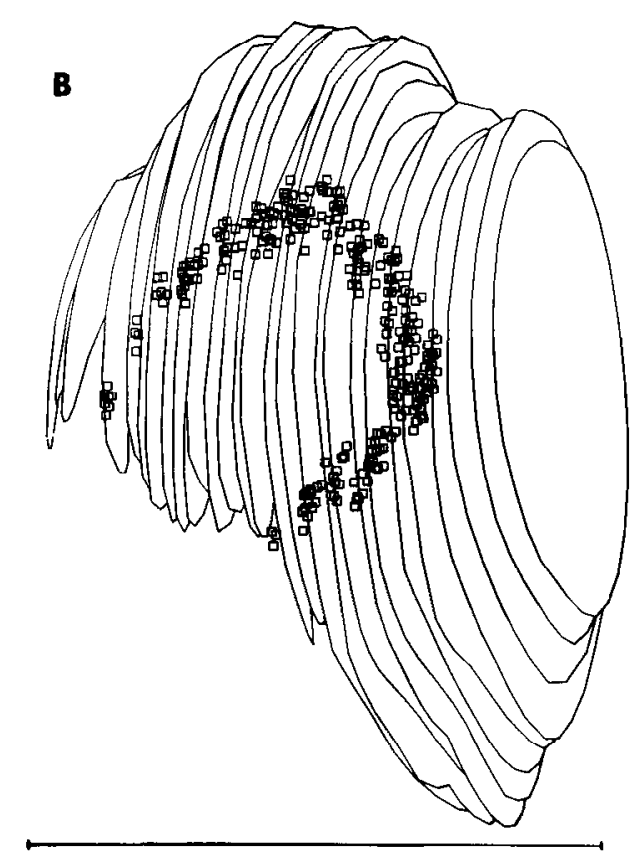

Another consideration related to the magnitude of the terminal displacement has to do with the assumption that the circle representing the projection of the labeled retinal annulus is centered on the tectal surface (Fig. 7). This is not quite accurate, since, as discussed above, the labeled retinal annulus is not centered on the retinal surface; rather, it is displaced ventral to the horizontal meridian by about $18.5^{\circ}$ and temporal to the vertical meridian by about $6.5^{\circ}$. Therefore, the circle representing its tectal projection is correspondingly displaced medially and rostrally from the tectal center. Calculations show that when these adjustments are considered the magnitude of $\delta$ changes by less than $1 \%$.

The estimates of terminal displacement are more substantially affected, however, by the assumption that the original projection was retinotopically organized at the time of the ${ }^{3} \mathrm{H}$-thymidine injection in larval and early juvenile fish. The position of the final projection site of the annulus of labeled ganglion cells is not at issue, at least for the 3 largest fish with longest survival times; Meyer's (1978) electrophysiological maps have established the retinotopy of the projection in goldfish of this size. What is at issue is the location of the original projection site, i.e., the point of origin of the arrow in Figure 7. Let us assume, as a worst case, that the map was reversed, so that terminals from temporal retina originally projected to the caudal edge rather than the rostral tectal boundary. The distances over which they would have moved in the 2 oldest fish, F37/533 and F < $50 / 646$, are then reduced by 26 and $20 \%$, respectively. Thus, the predicted displacements are still over $1 \mathrm{~mm}$ after $1-2$ years of growth.

Up to now I have discussed only the magnitude of the shift, but these movements also have a defined direction. The first point to make is that the displacements are generally in the caudal direction, although this statement requires some clarification. The vector that originates at the rostral tectal pole, and is depicted in Figure 7, is shown as if it lay along the rostrocaudal axis of the tectum, but in actuality it deviates slightly medially from a true caudal course because of the $20 \%$ asymmetry in growth by cell addition along the dorsoventral axis of the retina. The remaining vectors that connect the original and final projection sites of other retinal terminals are similarly skewed medially (not shown).
A second consideration is that because of the slightly greater rate of growth of retinal area compared to tectal area (on a verage, $12.7 \%$; see Table 1), the movements of retinal terminals have a compressive component. As mentioned above, this leads to larger movements by more rostrally placed terminals, but it also leads to the prediction that those terminals at the caudalmost tectal rim actually move rostrally, at least during their initial growth increment. This idea was discussed in detail in our earlier study of older fish (Raymond and Easter, 1983). What is important in the present context is that once again the pattern seen in adult goldfish is established at larval stages.

\section{Discussion}

Several reports have appeared recently in support of the suggestion that retinotectal connections shift as fish grow (goldfish: Cook et al., 1983; Easter and Stuermer, 1984; Stuermer, 1984; Stuermer and Easter, 1984; perciform fish: Rusoff, 1984). All of these studies used axonal transport of HRP to visualize the pathways that retinal fibers take within the tectum of adult fish. The trajectory of the retinal fibers as they course through the tectum to reach their site of termination is complex, but the pattern is consistent with a progressive caudalward movement of most retinal fibers during the time they have been in the tectum. A model that predicts the pathways taken, but not the distances traveled, by retinal axons as they move in the growing tectum was developed in detail by Easter and Stuermer (1984).

According to their model, the axon of each retinal fiber as it courses through the tectum is divided into 3 segments: a fascicular and an extrafascicular part and a terminal arbor (Easter and Stuermer, 1984; Stuermer, 1984; Stuermer and Easter, 1984). It is the extrafascicular segment that most concerns us here, since it traces out the route that the terminal arbor followed as it moved across the tectum from its original site of termination to its present location. These extrafascicular segments are up to about $1 \mathrm{~mm}$ long (Easter and Stuermer, 1984). Cook et al. (1983) and Stuermer (1984) showed that the length of the extrafascicular segment varied systematically with tectal location, such that the longest ones were in rostral tectum near the midline of the tectal lobe. The goldfish used by Easter and Stuermer were large adults, 17-20 cm standard length, whereas those used by Cook et al. were small, $3.5-7.5 \mathrm{~cm}$ standard length; yet despite this 


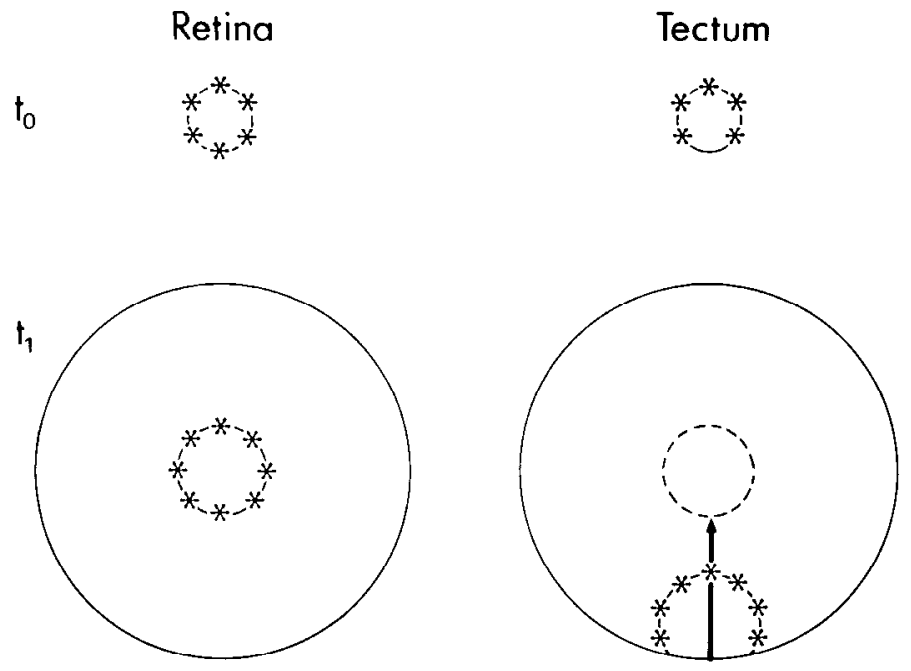

Figure 7. Schematic of autoradiographic results. At time $t_{0},{ }^{3} \mathrm{H}$-thymidine was injected, and dividing cells wcrc labcled (*) in the circumferential germinal zone of the retina and partial annular germinal zone of the tectum. Later, at time $t_{1}$, the annular zone of labeled retinal ganglion cells that defines the original retina is surrounded by new retina; the partial annulus of labeled tectal cells that defines the original tectum remains attached to the tectal boundary along its nonlabeled (rostral) segment. Dashed circle in tectum represents the current (at time $t_{1}$ ) site of projection of the labeled retinal ganglion cells. Arrow indicates the movement of terminals that originally projected to the rostral tectal border. The sizes of retina and tectum have been arbitrarily equated, though retinal area is actually greater than tectal area (see Table 1).

discrepancy in size and, by inference, age, both groups agree that the maximum length of the extrafascicular segment is on the order of $1 \mathrm{~mm}$.

These observations are entirely consistent with the predictions of the present paper. The model presented here was based on measurements of the extent and morphology of growth in retina and tectum using ${ }^{3} \mathrm{H}$-thymidine as a marker, and it predicts that optic terminals can shift caudally $1.5-1.8 \mathrm{~mm}$. In the HRP studies (Cook et al., 1983; Easter and Stuermer, 1984), the extrafascicular segments were up to $1.0 \mathrm{~mm}$ long, but since this value was not corrected for histological shrinkage in either study, its actual value is probably somewhat larger, and therefore quite close to that predicted by the thymidine study. Note also that the longest measured extrafascicular segments were in rostral tectum, near the midline, precisely the location of the maximal shifts predicted here (Fig. 7).

With regard to direction, most of the extrafascicular segments coursed caudally (Cook et al., 1983; Easter and Stuermer, 1984; Stuermer, 1984). These studies did not report a tendency to slide medially as the fibers moved caudally, but this component would be difficult to visualize in HRP-labeled axons in tectal whole-mounts, which have been nearly bisected along the rostrocaudal meridian in order to flatten the tectum onto a slide. Recent HRP studies (Cook et al., 1983; Easter and Stuermer, 1984; Rusoff, 1984; Stuermer, 1984), however, have revealed that the most caudally placed terminals are displaced rostrally, as predicted.

The results of the ${ }^{3} \mathrm{H}$-thymidine experiments also confirm and refine an earlier model describing displacement vectors of shifting retinal terminals in the growing adult goldfish tectum (Raymond and Easter, 1983). In that study, the tectal surface was modeled 2-dimensionally as a circular disc. During a 3 to 4 year period of growth in adult fish, the number of tectal cells was augmented by about 30\% (Raymond and Easter, 1983), whereas

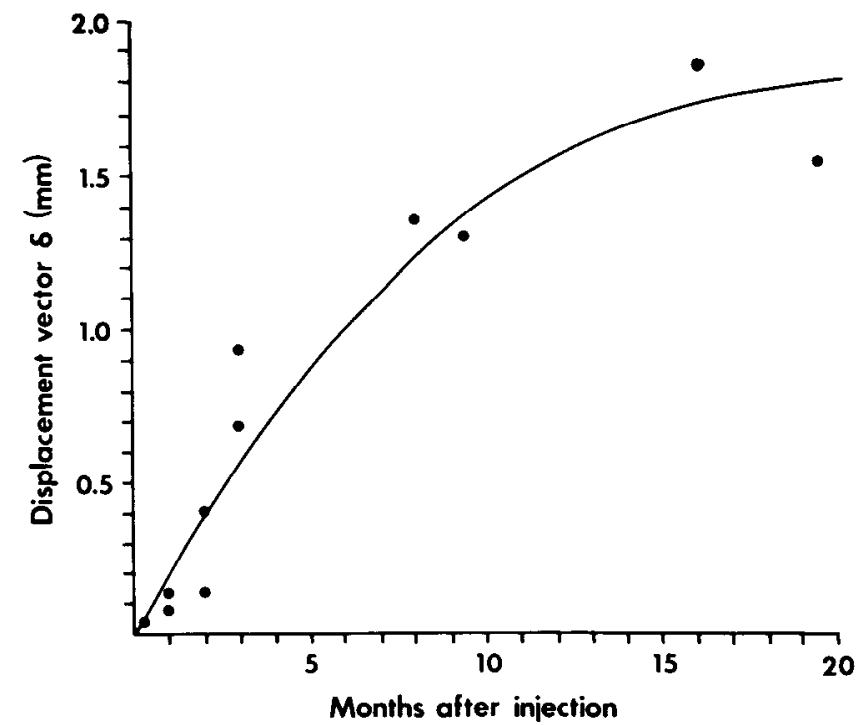

Figure 8. Displacement of retinal terminals, $\delta$, calculated as described in the text. This is a measure of the magnitude of the predicted movement of retinal terminals in the tectum during the interval plotted on the abscissa. Each point represents 1 fish. The smooth curve was drawn by eye through the data points. Note that the oldest fish, at 20 months, was smaller than the fish that survived for 16 months (see Table 1). For this reason, the value of $\delta$ in this animal is lower; it simply did not grow as much.

the number of optic axons increased by $100 \%$ (Easter et al., 1981). In the previous study, however, no attempt was made to estimate the magnitude of the shift of optic terminals. The displacements of terminals originating from ganglion cells added in the adult would be much less than those born during larval and juvenile phases, since their magnitude depends directly on the amount of cell addition.

The magnitudes of the movements of retinal terminals in young goldfish are comparable to those seen by Reh and Constantine-Paton (1984) in Rana tadpoles. Their study is the best attempt to date to directly visualize and quantify the movements of retinal terminals in the tectum. These authors found that terminals from ganglion cells near the optic disc shifted by about $700 \mu \mathrm{m}$ (or $1.4 \mathrm{~mm}$ when corrected for $40-50 \%$ histological shrinkage). The measurements were made with reference to a stable ${ }^{3} \mathrm{H}$-thymidine marker over a 6 week period extending from larval stage XII to postmetamorphic stage XXV. The rate of movement was $33 \mu \mathrm{m} / \mathrm{d}$, somewhat greater than that observed in young goldfish. A more substantive difference between tadpoles and fish is that in Rana during this 6 week period of growth the total tectal length increases by only $10 \%$ (estimated from fig. 4 in Reh and Constantine-Paton, 1984), which means that the surface area increases about 2 -fold. The implication is that much of the movement of optic terminals in the tectum of larval frogs represents colonization of caudal rcgions that are late to mature, whereas in juvenile fish the terminals move into newly created regions of tectum that did not exist earlier.

The most important findings of this study are the following. First, more than $95 \%$ of the total area of retina or tectum in an adult goldfish can be composed of cells generated postembryonically. Second, the pattern of cell addition in the retinal and tectal germinal zones is constant throughout postembryonic life, and at all times the pattern is incongruent between retina and tectum. Third, a quantitative model of tectal growth based on analysis of brains labeled with ${ }^{3} \mathrm{H}$-thymidine during larval and early juvenile life predicts that in general retinal fibers shift 
caudally in the tectum with growth. The fibers that move the farthest originate from temporal retina; they move caudally and slightly medially at a rate of about $5 \mu \mathrm{m} / \mathrm{d}$. The most intriguing and most significant implication of the hypothesis of shifting retinotectal terminals as formulated here is that individual terminal arbors continually acquire new sets of postsynaptic partners. This inference can be nothing more than speculation, however, until it is shown that in very young goldfish retinal fibers form an orderly retinotectal map and make synaptic connections with the tectal cell partners that are appropriate at that time.

\section{References}

Allee, W. C., A. J. Finkel, and W. H. Hoskins (1940) The growth of goldfish in homotypically conditioned water; a population study in mass physiology. J. Exp. Zool. 84: 417-443.

Chung, S.-H., M. J. Keating, and T. V. P. Bliss (1974) Functional synaptic relations during the development of the retino-tectal projection in amphibians. Proc. R. Soc. London [Biol.] 187: 449-459.

Constantine-Paton, M., E. C. Pitts, and T. A. Reh (1983) The relationship between retinal axon ingrowth, terminal morphology, and terminal patterning in the optic tectum of the frog. J. Comp. Neurol. 218: 297-313.

Cook, J. E., E. C. C. Rankin, and H. P. Stevens (1983) A pattern of optic axons in the normal goldfish tectum consistent with the caudal migration of optic terminals during development. Exp. Brain Res. 52. $147-151$

Easter, S. S., Jr., and C. A. O. Stuermer (1984) An evaluation of the hypothesis of shifting terminals in goldfish optic tectum. J. Neurosci. 4: 1051-1063.

Easter, S. S., Jr., P. R. Johns, and L. Baumann (1977) Growth of the adult goldfish eye. I. Optics. Vision Res. 17: 469-477.

Easter, S. S., Jr., A. C. Rusoff, and P. E. Kish (1981) The growth and organization of the optic nerve and tract in juvenile and adult goldfish. J. Neurosci. 1: 793-811.

Fraser, S. E. (1983) Fiber optic mapping of the Xenopus visual system: Shift in the retinotectal projection during development. Dev. Biol. 95: 505-511.

Gaze, R. M., M. J. Keating, and S.-H. Chung (1974) The evolution of the retinotectal map during development in Xenopus. Proc. R. Soc. London [Biol.] 185: 301-330.

Gaze, R. M., M. J. Keating, A. Ostberg, and S.-H. Chung (1979) The relationship between retinal and tectal growth in larval Xenopus: Implications for the development of the retino-tectal projection. J. Embryol. Exp. Morphol. 53: 103-143.

Holt, C. E., and W. A. Harris (1983) Order in the initial retinotectal map in Xenopus: A new technique for labeling growing fibers. Nature 301: 13-19.

Jacobson, M. (1976) Histogenesis of retina in the clawed frog with implications for the pattern of development of retinotectal connections. Brain Res. 103: 541-545.

Jacobson, M. (1977) Mapping the developing retinotectal projection in frog tadpoles by a double label autoradiographic technique. Brain Res. 127: 55-67.

Johns, P. R. (1977) Growth of the adult goldfish eye. III. Source of the new retinal cells. J. Comp. Neurol. 176: 343-358.

Johns, P. R. (1982) Formation of photoreceptors in larval and adult goldfish. J. Neurosci. 2: 178-198.

Johns, P. R., and S. S. Easter, Jr. (1977) Growth of the adult goldfish cyc. II. Increase in retinal cell number. J. Comp. Neurol. 176: 331342.

Jones, E. G. (1981) Development of connectivity in the cerebral cortex. In Studies in Developmental Neurobiology, W. Maxwell Cowan, ed., pp. 354-394, Oxford U. P., New York.
Kajishima, T. (1960) The normal developmental stages of the goldfish, Carassius auratus. Jpn. J. Ichtyol. 8: 20-28.

Kirsche, W., and K. Kirsche (1961) Experimentelle Untersuchungen zur Frage der Regeneration und Funktion des Tectum opticum von Carassius carassius L. Z. Mikrosk. Anat. Forsch. 67: 140-182.

Lazar, G. Y. (1973) The development of the optic tectum in Xenopus laevis: A Golgi study. J. Anat. 116: 347-355.

LeVay, S., T. N. Wiesel, and D. H. Hubel (1980) The development of ocular dominance columns in normal and visually deprived monkeys. J. Comp. Neurol. 191: 1-51.

Lichtman, J. W., and D. Purves (1980) The elimination of redundant preganglionic innervation to hamster sympathetic ganglion cells in early postnatal life. J. Physiol. (Lond.) 301: 213-228.

Longley, A. (1978) Anatomical mapping of retino-tectal connections in developing and metamorphosed Xenopus: Evidence for changing connections. J. Embryol. Exp. Morphol. 45: 249-270.

Matsui, Y. (1981) Goldfish Guide, L. C. Betts, ed., T.F.H. Publications, Hong Kong.

Meek, J., and N. A. M. Schellart (1978) A Golgi study of goldfish optic tectum. J. Comp. Neurol. 182: 89-121.

Meyer, R. L. (1977) Eye-in-water electrophysiological mapping of goldfish with and without tectal lesions. Exp. Neurol. 56: 23-41.

Meyer, R. L. (1978) Evidence from thymidine labeling for continuing growth of retina and tectum in juvenile goldfish. Exp. Neurol. 59: 99-111.

Rahmann, H., and G. Jeserich (1978) Quantitative morphogenetic investigations on fine structural changes in the optic tectum of the Rainbow Trout (Salmo gairdneri) during ontogenesis. Wilhelm Roux's Archives of Developmental Biology 184: 83-94.

Raymond, P. A. (1983) How retina and tectum grow in postembryonic goldfish. Soc. Neurosci. Abstr. 9: 760.

Raymond, P. A. (1985) Cytodifferentiation of photoreceptors in larval goldfish: Delayed maturation of rods. J. Comp. Neurol. 236: 90-105.

Raymond, P. A., and S. S. Easter, Jr. (1983) Postembryonic growth of the optic tectum in goldfish. I. Location of germinal cells and number of neurons produced. J. Neurosci. 3: 1077-1091.

Reh, T. A., and M. Constantine-Paton (1983) Qualitative and quantitative measures of plasticity during the normal development of the Rana pipiens retinotectal projection. Dev. Brain Res. 10: 187-200.

Reh, T. A., and M. Constantine-Paton (1984) Retinal ganglion cell terminals change their projection sites during larval development of Rana pipiens. J. Neurosci. 4: 442-457.

Rusoff, A. C. (1984) Paths of axons in the visual system of perciform fish and implications of these paths for rules governing axonal growth. J. Neurosci. 4: 1414-1428.

Schmidt, J. T., C. M. Cicerone, and S. S. Easter, Jr. (1978) Fxpansion of the half retinal projection to the tectum in goldfish: An electrophysiological and anatomical study. J. Comp. Neurol. 177: 257-278.

Scott, T. M., and G. Lazar (1976) An investigation into the hypothesis of shifting neuronal relationships during development. J. Anat. 121: 485-496.

Straznicky, K., and R. M. Gaze (1971) The growth of the retina in Xenopus laevis: An autoradiographic study. J. Embryol. Exp. Morphol. 26: 67-79.

Straznicky, K., and R. M. Gaze (1972) The development of the tectum in Xenopus laevis: An autoradiographic study. J. Embryol. Exp. Morphol. 26: 87-115.

Stuermer, C. A. O. (1984) Rules for retinotectal terminal arborizations in the goldfish optic tectum: A whole-mount study. J. Comp. Neurol. 229: 214-232.

Stuermer, C. A. O., and S. S. Easter, Jr. (1984) Rules of order in the retinotectal fascicles of goldfish. J. Neurosci. 4: 1045-1051. 